\title{
Validating a measurement scale for entrepreneurial actions for sustainable corporate entrepreneurship using confirmatory factor analysis
}

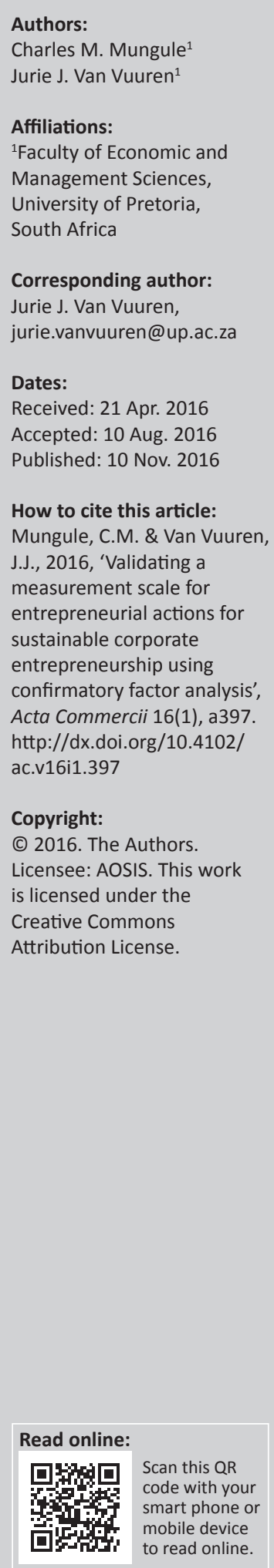

Orientation: Sustainable corporate entrepreneurship, which is achieved through entrepreneurial actions, has become a useful strategy for enhancing organisational performance. However, there seems to be no psychometrically sound and valid measurement instrument for such entrepreneurial actions.

Research purpose: The study aimed at addressing this issue by proposing and empirically assessing a measurement instrument for entrepreneurial actions to determine its validity and psychometric attributes.

Motivation for the study: Since entrepreneurial actions have been identified as an essential vehicle for translating management's entrepreneurial intentions into meaningful organisational achievements, a measurement instrument for entrepreneurial actions with acceptable psychometric attributes would greatly benefit the field of sustainable corporate entrepreneurship.

Research design, approach and method: The study used data from Zambia with a sample of 646 managers from organisations in eight different economic sectors. Zambia was chosen for the study because such a study was never undertaken in the country thereby making a valuable contribution to the country's body of entrepreneurship knowledge. Data analysis and measurement were mainly conducted using Confirmatory Factor Analysis.

Main findings: The study findings indicated that the postulated four-item measurement instrument was relatively stable and psychometrically sound with acceptable content and construct validity.

Practical/managerial implications: The study findings amplified the role of managers in instigating entrepreneurship within established organisations through their entrepreneurial actions for the purposes of ensuring achievement of sustainable corporate entrepreneurship and sustained performance.

Contribution/value-add: The findings of this study contributed immensely to the literature on sustainable corporate entrepreneurship useful for research and teaching.

\section{Introduction}

Scholars are generally cognisant of the role entrepreneurial actions play in instigating performance in organisations of any size, although this relationship has been assessed in various ways over time (Kuratko, Hornsby \& Bishop 2005a:277; Kuratko et al. 2005b:704). Entrepreneurial actions are increasingly being considered by organisations as an essential ingredient for survival and achieving competitive advantage in a volatile and rapidly changing global market (Ireland et al. 2001; Kuratko et al. 2005b). Availability of a psychometrically sound as well as valid and reliable instrument to measure entrepreneurial actions for sustainable corporate entrepreneurship (CE) would significantly contribute to an increased uptake of CE strategy by established organisations while at the same time advancing our knowledge of the CE phenomenon. One notable attempt in this respect was by Kuratko et al. (2005a), who developed a measurement instrument used to measure entrepreneurial actions in a study of manager's corporate entrepreneurial actions and job satisfaction. However, as for the development of an appropriate measuring instrument for entrepreneurial actions for sustainable CE goes, there is yet more scholarly work to be done in order to enhance our understanding and benefit the field of sustainable CE. 


\section{Research question and objectives}

This study attempted to empirically assess a measurement instrument for entrepreneurial actions as regards sustainable $\mathrm{CE}$ within established organisations. The central research question endeavoured to determine whether the hypothesised measurement instrument for these actions had acceptable psychometric attributes. Specifically, the study was concerned with the reliability, validity and unidimensional capacity of the measurement instrument. In this regard, reliability refers to the instrument's ability to measure the construct of interest consistently while validity refers to how successfully the instrument accurately measures the construct of interest (Hair et al. 2010). Unidimensionality of a measurement scale refers to the scale's items being strongly associated with each other and representing a single construct (Hair et al. 2010:125). Furthermore, the study also aimed at establishing whether the hypothesised measurement instrument for entrepreneurial actions for sustainable CE had acceptable intercultural psychometric portability. The hypothesised measurement instrument, with the exception of item EA4, was developed and applied in diverse demographic and cultural contexts (Kuratko et al. 2005a). Many psychometric instruments fail the test of intercultural psychometric portability (Dolnicar \& Grün 2007; Van Wyk \& Adonisi 2011). Accordingly, the research objectives were (1) to assess measurement reliability of the hypothesised measurement instrument for entrepreneurial actions relating to sustainable CE; (2) to assess construct validity of the said measurement instrument; (3) to determine whether this instrument was unidimensional; (4) to determine the intercultural psychometric portability of the hypothesised instrument and (5) to make a contribution to the CE knowledge.

\section{Literature review}

Entrepreneurship within established organisations: Kuratko (2013:5) posits that entrepreneurship is a 'dynamic process of vision, change, and creation'; it is the process by which new organisations come into existence. However, a wide range of activities such as 'creation, founding, adapting, and managing a venture' have been used to define the phenomenon (Kusumsiri \& Jayawardane 2013:26). CE is the term scholars generally use to refer to entrepreneurship practiced within established organisations and the scope of the phenomenon has ultimately expanded significantly, becoming more refined (Corbett et al. 2013:812). However, different opinions still exist among CE researchers regarding the attributes that must exist in order to label an organisation entrepreneurial (Covin \& Miles 1999:49), resulting in different definitions and terms used for the phenomenon, while the CE construct itself takes many forms (Menzel, Aaltio \& Ulijn 2007:733; Sharma \& Chrisman 1999:13).

Covin and Miles (1999:50) define CE as the process of innovation coupled with the presence of the objective to rejuvenate or purposely redefine organisations, markets or industries in order to create or sustain competitive superiority. CE is considered to adopt five distinct forms (Covin \& Miles 1999:50-54; Morris, Kuratko \& Covin 2011:99-101): (1) sustained regeneration: the $\mathrm{CE}$ phenomenon where the organisation regularly and continuously introduces new products and services or enters new markets; (2) organisational rejuvenation: the CE phenomenon in terms of which the organisation seeks to sustain or improve its competitive standing by altering its internal processes, structures and/or capabilities; (3) strategic renewal: the $\mathrm{CE}$ phenomenon where the organisation seeks to redefine its relationship with its markets or industry competitors by fundamentally altering how it competes; (4) domain redefinition: the $\mathrm{CE}$ phenomenon in which the organisation proactively creates a new product market arena that others have not recognised or actively sought to exploit and (5) business model reconstruction: a form of CE where an organisation applies entrepreneurial thinking to the design or redesigning of its core business model(s) in order to improve its operational efficiencies or otherwise differentiate itself from industry competitors in ways valued by the market. Therefore, entrepreneurship is more than just individual entrepreneurial activities performed by employees or managers. The phenomenon becomes integrated into the entire organisational fabric and 'captures the essence of what an organisation is about and how it operates' (Morris et al. 2011:52). The literature indicates that $\mathrm{CE}$ exerts a direct and positive influence on organisational performance, as it is interwoven with the organisation's mission and vision, strategies, objectives, structures and everyday operations as well as the overall organisational culture (Covin \& Slevin 1991; Morris et al. 2011:52). CE is essentially the effort of promoting innovation within an existing organisation through products, processes, strategies, domain or business models in order to discover, assess and ultimately exploit attractive economic opportunities based on a long-term perspective.

In the field of entrepreneurship, the term sustainability takes on many different conceptualisations and dimensions. Some researchers' perspectives are those of sustainable entrepreneurship in relation to environmental stewardship (e.g. Miles, Munilla \& Darroch 2009; Schaltegger \& Wagner 2011; Shepherd \& Patzelt 2011). However, other researchers use the term 'sustainability' in relation to corporate entrepreneurial behaviour, implying ongoing improvements or enduring entrepreneurial capabilities within established organisations, resulting in a sustainable competitive advantage and sustained performance, and employ terms such as 'sustainable' CE (Kelly 2011:74), 'sustaining CE' (Kuratko, Hornsby \& Goldsby 2004:79), 'sustainable competitive advantage' (Urban \& Nikolov 2013:384), 'strategic entrepreneurship' (Hitt et al. 2011:57) and 'continued entrepreneurship' (Davidsson 1991:405) to define the phenomenon. Ultimately, CE should lead to sustainability of a venture resulting from the organisation's ability to ensure continuous improvement and radical innovation (Morris et al. 2011:375, 403). This study uses the term 'sustainability' in this context of ongoing improvements or enduring entrepreneurial capabilities within established organisations, resulting in a sustainable competitive advantage and sustained performance. By adopting the CE typology of Covin and Miles (1999) and Morris et al. (2011), we define sustainable CE as the effort of promoting sustained innovation relating to products, processes, strategies, domain or business models within an existing organisation in order to discover, assess and ultimately exploit 
attractive entrepreneurial opportunities, to bring about ongoing improvement in organisational performance.

The Theory of Entrepreneurial Actions for Sustainable corporate entrepreneurship: Entrepreneurial actions are activities upon which organisations embark to exploit entrepreneurial opportunities unnoticed or unexploited by rivals; these actions constitute a fundamental organisational behaviour in which organisations move into new markets, seize new customers and/or combine existing resources in new ways (Kuratko et al. 2005a:276; Smith \& Di Gregorio 2002). In this regard, entrepreneurial actions are critical in pursuing a CE strategy as they are a conduit for exploiting identified competitive advantages. It is evident from the literature that the construct entrepreneurial actions has been operationalised variously and used in different contexts by several scholars (e.g. Ireland et al. 2001; Kuratko, Ireland \& Hornsby 2001; Kuratko et al. 2005a; Simon \& Shrader 2012; Wensley et al. 2011), while others have used it without offering any operational definition (e.g. Hornsby et al. 2013). For instance, as noted, Kuratko et al. (2005a:276) define entrepreneurial actions as 'any newly fashioned set of actions through which companies seek to exploit entrepreneurial opportunities that rivals have not noticed or exploited'. This definition is similar to the one offered by Ireland et al. (2001:50), hinted at above, who define entrepreneurial actions as 'newly fashioned behaviours through which companies exploit opportunities others have not identified or exploited' and are 'oriented to novelty'. According to Kuratko et al. (2001:60), the defining characteristic of entrepreneurial actions is novelty in relation to new resources, markets or customers or a new combination of resources, markets and customers.

Furthermore, Kuratko et al. (2001:61), posit that 'product, process, and market innovations' are often a result of 'newly fashioned entrepreneurial actions', through which organisations exploit opportunities on a first-mover basis. As mentioned, Smith and Di Gregorio (2002) postulate that these entrepreneurial actions make up a fundamental organisational behaviour by which organisations move into new markets, seize new customers and/or undertake new combinations of existing resources. According to Wensley et al. (2011:133), entrepreneurial actions involve 'arranging or organising the human and capital assets under someone's control for the purposes of creating a viable profit-making entity'. However, these authors (Wensley et al. 2011:133) clearly conceptualise entrepreneurial actions as various actions undertaken to achieve specific entrepreneurial objectives, such as successfully achieving the creation of customer capital and operationalise the concept in terms of: (1) knowledge exploration practices that allow organisational members to call upon aspects of practice latent in the periphery as they are needed, instead of deciding ahead of time what an individual needs to know and making this explicitly available to the exclusion of everything else; (2) the presence of open-minded practices within an organisation, which leads to the questioning of established organisational approaches to problem solving and organisational beliefs, even when these have led to successful outcomes in the past and (3) knowledge exploitation practices. Thus, there are different types of entrepreneurial actions.

This study distinguishes the two concepts of entrepreneurial actions and CE as separate but related constructs. On the one hand, entrepreneurial actions pertaining to established organisations are the specific entrepreneurial behaviours of managers, as well as of the other individual employees within an organisation and act as a conduit through which CE is practised (Hitt et al. 2001). CE, on the other hand, is the 'ostensibly larger topical domain' (Covin \& Lumpkin 2011:855) embracing all aspects of entrepreneurship inside established organisations such as entrepreneurial orientation/ posture, strategic entrepreneurship, corporate venturing and intrapreneurship. In other words, CE is the bigger and overarching phenomenon, an overall construct capturing all entrepreneurial activities within established business organisations (De Jong et al. 2011:4). Indeed, in this respect, CE includes entrepreneurial behaviour and orientation in established organisations (Urbano \& Turró 2013).

However, entrepreneurial actions or behaviours can be considered to be the 'conduit' of CE (Hitt et al. 2001). As Kuratko et al. (2001:61) put it, such actions are in fact 'novel behaviours' that the organisation

... intends to use to pursue opportunities; entrepreneurship
captures the full set of entrepreneurial actions the firm takes to
create, renew, or innovate; when practiced in large organisations,
entrepreneurial actions are the foundation for corporate
entrepreneurship, a specific application of entrepreneurship;
and, when entrepreneurial actions are the foundation on which a
firm's strategy is built, a corporate entrepreneurship strategy is
being implemented.

Entrepreneurial actions are actually specific to identified entrepreneurial activity in a given decision-making context for the organisation and do reflect a unique decision environment, ranging from new venture creation to product introduction in a dynamic environment (Simon \& Shrader 2012:292-293). For example, Simon and Shrader (2012), in their empirical study on entrepreneurial actions and optimistic overconfidence, examined five different types of entrepreneurial actions, including venture creation, introducing products that entail more utilisation of the organisation's resources and introducing products in hostile or dynamic environments.

By adapting the definitions offered by Kuratko et al. (2005a:276) and Ireland et al. (2001:50), this study defines managers' entrepreneurial actions for sustainable CE as a set of newly fashioned activities within an established organisation aimed at ensuring ongoing exploitation of entrepreneurial opportunities unexploited by rivals. Satisfaction with organisational outcomes in relation to the implemented entrepreneurial activities is an important aspect of these entrepreneurial actions as it creates the basis for the decision whether to sustain, enhance or revise such activities in order to achieve a sustainable competitive advantage and ongoing improvements in performance. Managers' entrepreneurial 
actions have been identified as playing an important role in instigating entrepreneurship within established organisations and are considered as 'critical pathways to competitive advantage and improved performance' (Kuratko et al. 2001:60). In this respect, their actions are the channels by which sustainable CE and sustained organisational performance can be achieved. The presence of an appropriate CE climate or of organisational antecedents is critical in instigating these entrepreneurial actions. However, managers at different levels have differing views concerning the feasibility and/or desirability of the organisational antecedents (top management support, rewards, time availability, work discretion and organisational boundaries) for promoting entrepreneurial actions (Hornsby et al. 2009:241).

According to Kuratko et al. (2005b:708), managers undertake entrepreneurial actions only once they are convinced that the organisational antecedents to those actions exist and when the managers are in fact aware of their existence. Once individuals recognise as well as interpret these antecedents as indicators of the existence of an internal environment supportive of such actions, they are led to assess their capacities for entrepreneurial undertaking on the basis of what they perceive to be a set of organisational resources, opportunities and obstacles to engaging in entrepreneurial actions (Chen, Greene \& Crick 1998; Kuratko et al. 2005a:280). This is critical for sustaining CE, as it instigates continuity or discontinuity of current entrepreneurial actions and was the reason the researchers added the fourth item to measure entrepreneurial actions for sustainable CE.

Therefore, entrepreneurial actions do not occur in a vacuum as they actually take place within the context of the organisation's complete range of actions (Dess, Lumpkin \& Covin 1997). In this regard, an organisation's entrepreneurial actions could have a mediating effect on the ability of a corporate climate to stimulate sustainable CE. Therefore, an appropriate measurement instrument for entrepreneurial actions is fundamental to the study of corporate entrepreneurial climate and sustainable CE. Because an organisation's entrepreneurial actions constitute its fundamental behaviour by which it penetrates new markets, seizes new customers and/or undertakes new combinations of existing resources (Smith \& Di Gregorio 2002), it is expected that organisations exhibiting more entrepreneurial actions will tend to be on the path to sustainable CE.

\section{Assessment of measurement instrument for entrepreneurial actions}

This study attempted to empirically assess an instrument for measuring entrepreneurial actions for sustainable CE within established organisations, with a view to constructing a more psychometrically sound measure of the phenomenon, based on the instrument to be tested. Accordingly, the study was aimed at assessing reliability, validity and unidimensionality of the postulated measurement scale, as well as establishing the scale's intercultural psychometric portability.
An assessment of measurement reliability: The consistency of a particular measurement instrument's scores is referred to as the measurement reliability (Hair et al. 2010; Said, Badru \& Shahid 2011; Streiner 2003). Scholars usually use Cronbach's alpha to assess this, with a commonly accepted reliability threshold of coefficient alpha $(\alpha) \geq 0.70$. In the context of structural equation modelling (SEM), squared multiple correlations (SMCs), factor loadings and error variances are used to measure reliability. According to Hooper, Coughlan and Mullen, (2008), items that have SMCs less than 0.20 should be considered for deletion because such levels of SMCs are an indication that the item is measuring something else than it was intended to do. Standardised loadings are used to measure individual indicator reliability with an ideal threshold of at least 0.70 , giving a reliability of at least 0.50 ; that is, at least $50 \%$ of the measure's explained variance should be a function of its factor (Bagozzi \& Yi 2012).

An assessment of construct validity: The extent to which a set of measured items reflects the theoretical latent construct the items are meant to measure is known as the construct validity (Hair et al. 2010:708; Westen \& Rosenthal 2003:608-609). In this respect, it essentially involves the accuracy of the measurement itself, and this is one of the main objectives of Confirmatory Factor Analysis (CFA): to assess the construct validity of a postulated measurement theory (Hair et al. 2010:709). To do so, the study examined discriminant, convergent and face validity of the postulated measurement scale (Hair et al. 2010:709-710). In addition to the above, the underlying theory is essential when making a decision about construct validity. Theoretical support, rather than just empirical justification, should be the basis for model re-specification (Hair et al. 2010:647).

Convergent validity is the extent to which items that are indicators of a specific construct converge or share a high proportion of variance in common (Hair et al. 2010:710). When indicators to latent variables correlate with each other to an acceptable extent, then convergent validity is achieved. Based on the measurement model's goodness of fit (GOF), the conventional rule of thumb suggests that convergent validity is indicated when factor loadings are $\geq 0.70$ for all indicators (Garson 2012). According to (Van Dyne \& LePine 1998:112), evidence of convergent validity can also be established 'when each item has a statistically significant loading on its specified factor'. For the postulated measurement model, convergent validity was also assessed using average variance extracted (AVE) which, according to Hair et al. (2010:688), is a 'summary measure of convergence among a set of items representing a latent construct' and is the 'average percentage of variation explained (variance extracted) among the items of a construct'. In this respect, AVE $\geq 50 \%$ demonstrates that acceptable convergent validity has been achieved (Hair et al. 2010:709; Shook et al. 2004:400). For a construct with $\mathbf{n}$ items, its AVE can be computed as the total of all squared standardised factor loadings divided by the number of items (Hair et al. 2010:709).

Discriminant validity is the extent to which a construct is truly distinct from other constructs - the higher the discriminant 
validity, the more evident it is that the construct is unique from other constructs and vice versa, while the presence of cross-loadings implies a discriminant validity problem (Hair et al. 2010:710). In other words, when measures of different concepts are distinct, then discriminant validity is demonstrated, which is the case when there are low correlations among the concepts (Bagozzi et al. 1991). Unfortunately, different sources report different criteria for what could be considered as low correlation. However, Brown (2006) indicates that correlations $\geq 0.85$ between constructs count for poor discriminant validity. Basically in SEM, if the measurement model is found acceptable, such a model presents its own evidence of discriminant and convergent validity (Anderson \& Gerbing 1988; Shook et al. 2004). Acceptability of a measurement model would mean that it has fit indices $\geq 0.90$ and significant factor loadings $\geq 0.70$, with average variance extracted $\geq 50 \%$, showing acceptable convergent validity (Shook et al. 2004:400).

Face validity is the degree to which the content of the items is consistent with the way the construct is defined and is based solely on the researcher's judgement (Hair et al. 2010:710). This was vital for the study as the measurement model involved inclusion of a new item for the scale previously used in different research undertakings. Face (or content) validity was considered during the stage of piloting the hypothesised measurement instrument; the researchers were satisfied that all the four items were consistent with the definition of entrepreneurial actions for sustainable CE.

An assessment of unidimensionality: The literature reveals that measurement models that are psychometric must satisfy the attribute of unidimensionality, that is, 'valid and legitimate summing of rating scale items into an interpretable total score rest on the requirement that the items represent one common underlying (latent) variable' (Hagell 2014:457). In this respect, an underlying assumption and necessary requirement for creating a summated scale is that the testing of unidimensionality requires such a scale to consist of measurement 'items loading highly on a single factor' in that scale (Hair et al. 2010:125). According to Nazim \& Ahmad (2013:4), a measurement model is unidimensional if there are no redundant items, that is, items with factor loading $<0.5$ or items highly correlated to each other. Accordingly, if a measurement scale lacks unidimensionality, this 'cannot be compensated for by study design or analytical statistics, and hampers the understanding and usefulness of the outcomes' (Hagell 2014:457).

Therefore, it was deemed essential in this study to assess the hypothesised measurement instrument on the basis of the following hypotheses:

Hypothesis1: The proposed measurement instrument for entrepreneurial actions for sustainable CE has acceptable internal consistency.

Hypothesis 2: The proposed measurement instrument for entrepreneurial actions for sustainable CE has acceptable construct validity.
Hypothesis 3: The proposed measurement instrument for entrepreneurial actions for sustainable CE is a unidimensional scale.

Hypothesis 4: The proposed measurement instrument for entrepreneurial actions for sustainable CE has acceptable intercultural psychometric portability.

Three of the items or indicators for the hypothesised measurement instrument were adapted from the instrument developed by Kuratko et al. (2005a) and used as three singleitem latent variables to measure entrepreneurial actions in a study of managers' corporate entrepreneurial actions and job satisfaction. The three items are (Kuratko et al. (2005a): (1) the number of new ideas suggested, (2) the number of new ideas implemented and (3) the number of improvements implemented without official organisational approval. Unfortunately, the study by Kuratko et al. (2005a) did not report the reliability and validity of the measurement scale for entrepreneurial actions. Since then, there has been little scholarly effort exerted to refine the measurement instrument. Due to this void in literature, the researchers could not find appropriate previous research dealing with assessment of a measurement scale for entrepreneurial actions for sustainable CE. Therefore, this demonstrates a need for developing and validating a measurement instrument for entrepreneurial actions in an organisation so that it could be depended upon as an appropriate reflection of CE levels for the purposes of stimulating enhanced corporate competitiveness and performance.

Therefore, developing a psychometrically sound measurement instrument for managers' entrepreneurial actions pertaining to sustainable $\mathrm{CE}$ would be a significant contribution to the $\mathrm{CE}$ domain. In adapting the items developed by Kuratko et al. (2005a), the researchers also changed the wording by way of framing the items into statements requiring responses as indicated in Table 1.

Furthermore, this study aimed at assessing a measurement instrument for entrepreneurial actions for sustainable CE. However, the measurement instrument developed by Kuratko et al. (2005a) did not incorporate the aspect of continuity of entrepreneurial actions for the purposes of sustaining entrepreneurship within established organisations. In their model of sustained CE, Kuratko et al. (2004:79) demonstrated that sustainability is dependent on managers continuing to undertake innovative activities as well as their positive perceptions of these activities, which in turn results in further allocation of the needed organisational support and resources. In this respect, managers' satisfaction with performance based on their entrepreneurial actions serves as a feedback mechanism for either continuing or discontinuing current strategy (Kuratko et al. 2004; Morris et al. 2011) For instance, empirical research findings by Simon and Shrader (2012:291) indicated that both high and low levels of satisfaction with organisational performance were associated with the type of entrepreneurial actions relating to product introductions. Furthermore, Kuratko et al. (2004) point out 
TABLE 1: Measurement scale for entrepreneurial actions.

\begin{tabular}{lll}
\hline Latent factor & Observed variable & Item statement \\
\hline Entrepreneurial Actions & EA2 & $\begin{array}{l}\text { In our organisation, the number of improvements implemented without } \\
\text { organisational approval was on the increase over the past six months. } \\
\text { Over the past six months, the number of new ideas suggested in our organisation } \\
\text { increased greatly. } \\
\text { In our organisation, the number of new ideas implemented without official } \\
\text { organisational approval was on the increase in the past six months. } \\
\text { I am satisfied with the outcomes of my organisation's entrepreneurial activities as } \\
\text { they meet expectation. }\end{array}$ \\
\hline EA4 & Researchers
\end{tabular}

Source: First three items adapted from Kuratko et al. (2005a); last item developed by researchers

that managers' satisfaction with the outcomes pertaining to their actions should be both intrinsic (i.e. psychological) and extrinsic (i.e. tangible) in order for them to have undiminished participation.

Therefore, when adapting the Kuratko et al. (2005a) measurement, there was still a need to include an item that relates to managers' perceived satisfaction regarding the entrepreneurial activity being undertaken, that is, whether the activity meets expectations in order for it to be sustained or discontinued (Morris et al. 2011:74). In this regard, the scale used to measure the construct adapted three items developed by Kuratko et al. (2005a) and one item added by the researchers, as listed in Table 1.

As presented in Table 1, the measurement scale has four items as the observable variables: (1) improvements implemented without organisational approval, (2) new ideas suggested, (3) new ideas implemented without official organisational approval and (4) managers' satisfaction with the outcomes of implemented entrepreneurial activities of the organisation. Participants were asked to indicate their responses on a 5-point Likert scale of strongly disagree to strongly agree. Their responses indicated the extent to which they agreed or disagreed with each of the statements,

Figure 1 presents the hypothesised measurement model for entrepreneurial actions for sustainable CE.

The postulated CFA model presented graphically in Figure 1 shows the four items of interest (EA1 to EA4) and their respective error terms eEA1 to eEA4. The model provides the basis for the assessment of the measurement scale.

\section{Research methodology}

The collection, analysis and measurement of data were conducted in order to assess the postulated measurement scale. Two analyses were conducted: descriptive analysis to determine data properties and measurement reliability and CFA to test the proposed measurement scale in terms of GOF and construct validity.

Sampling and sample size: There is no accurate information available regarding size of the population elements of each industry in Zambia. The sample considered in this study comprised 646 senior, middle and junior managers. This was the first such study to be conducted in Zambia; therefore, the study makes a valuable contribution to the country's body

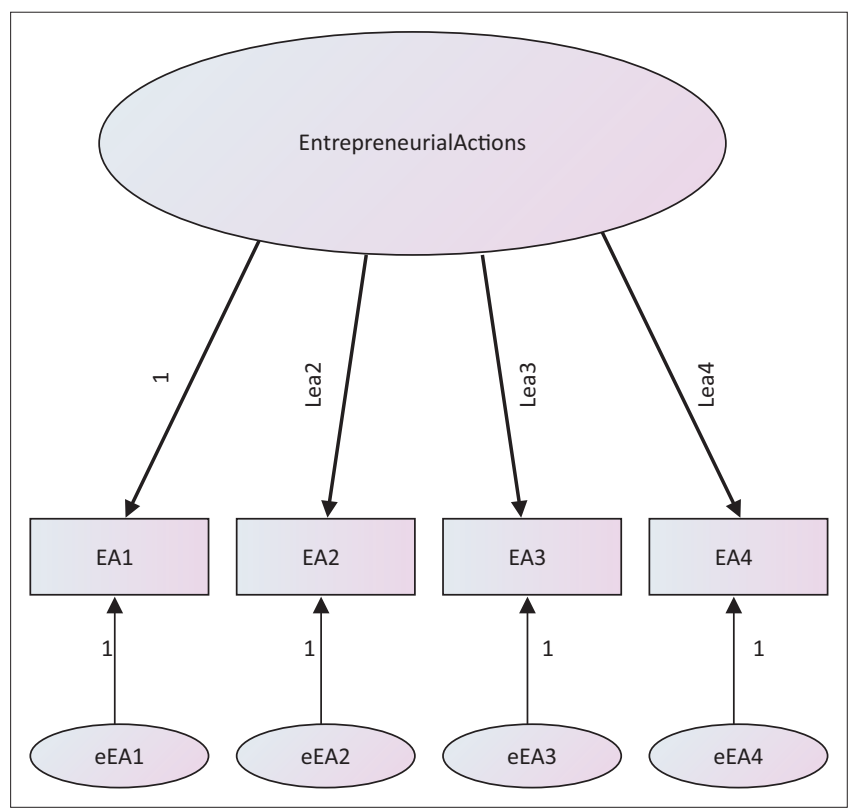

Source: AMOS Graphics

FIGURE 1: Hypothesised Confirmatory Factor Analysis model for entrepreneurial actions for sustainable corporate entrepreneurship.

of entrepreneurship knowledge. The selected participants at managerial level included system, process, information technology and conventional managers who were managing employees. The sampling approach aimed at ensuring reasonable distribution among the different industry sectors; however, participation in the survey was voluntary. Potential respondent organisations were identified through business directorates, trade associations, Chamber of Commerce membership lists and online databases. To ensure representativeness, a total of eight industry strata were included in the sample: manufacturing, agriculture/agro, banking/financial, tourism/hospitality, communication, mining, energy and service industries. The strata were largely identified through the Employment and Earnings Enquiry report of the Central Statistics Office of the Zambian Government (2009), which was used indicatively for apportioning sectoral participation in the study.

Organisations included in the sample were the established mid-sized to large organisations that needed to have been in operation for at least 4 years. It was expected that organisations in existence for 4-10 years would be experiencing early growth, while those in existence for 10 to $>15$ and 15 to $>20$ years would have reached the maturity and harvest/stability phases, respectively (Van Vuuren 2009). Therefore, it is expected that such organisations would be experiencing high levels of 
entrepreneurial activities. Data collection was carried out using a carefully developed measurement instrument, which also included biographical and organisational information. Various means were used to collect data, such as hand-delivering of the questionnaires to the premises of most of the participating organisations, by arranging for senior executives within the organisations to administer the questionnaires to their respective managers and by engaging data collection assistants. In total, 1620 questionnaires were distributed, of which 651 (40.2\%) were completed and collected.

Data analysis, cleaning and treatment of missing data: The study analysed the data using the IBM ${ }^{\circledR}$ Statistical Package for Social Sciences $\left(\mathrm{SPSS}^{\circledR}\right)$ software version 20. CFA procedures were conducted using Analysis of Moment Structures (AMOS) version 21, a visual SEM technique for the $\mathrm{IBM}^{\circledR} \mathrm{SPSS}^{\circledast}$. Important data analysis techniques used included the reliability and validity measures. At the empirical stage of data analysis, variables were used for the purposes of testing and measurement of the postulated relationships according to Cooper and Schindler (2008:61).

In order to improve data integrity or quality and produce more accurate study results, a data cleaning process was undertaken to identify and remove any errors or inconsistencies from the data (Burns \& Burns 2011). Collected data were cleaned and appropriate remedies were taken to enhance data analysis. As an initial step in detecting and removing any errors and inconsistencies, all the completed questionnaires were manually inspected. Five questionnaires that contained incomplete data were excluded, leaving a total of 646 questionnaires to process. Furthermore, IMB ${ }^{\circledR}$ SPSS $^{\circledast}$ software was used to analyse the data in order to obtain metadata about the data properties and detect any data quality problems such as data entry errors. Descriptive statistics were used to identify out-of-limit values, missing values as well as outliers. The descriptive analysis established that there was no missing data.

The study used CFA and confirmatory processes to test the model. The methodology was aimed at establishing an acceptable level of GOF and construct validity tests as well as measurement reliability. CFA was considered to be the appropriate technique as it would enable data analysis on the basis of an a priori-stated theoretical relationship between the underlying latent variable structure and the observed measures (Byrne 2004). This would assist in confirming the factors underlying a latent construct based on the existing theory regarding the nature of that construct (Hornsby et al. 2013:945). The sample size of 646 for this study was considered satisfactorily adequate for CFA procedures, which generally require a large sample size (Byrne 2010). Furthermore, CFA was used to detect the construct's unidimensionality (Anderson \& Gerbing 1988), which indicates a factor's adequate convergent and discriminant validity by recognising the factor as salient and independent of any other factor (Yoo \& Donthu 2001:35).

\section{Validating the measurement model for entrepreneurial actions for sustainable corporate entrepreneurship}

The classical test theory postulates that multi-item scales enhance minimisation of random measurement error as well as maximisation of measurement reliability and validity (Nunnally \& Bernstein 1994). Therefore, in line with the classical theory, the latent variable entrepreneurial actions for sustainable CE were represented by four measures of the same underlying construct. As mentioned, these four measures of entrepreneurial actions comprised three items developed by Kuratko et al. (2005a) and one added by the researchers.

The hypothesised model was tested on the basis of the formed four manifest variables (indicators) as described by Hair et al. (2010) which were subjected to CFA procedures. A measurement model's validity depends basically on two important factors (Hair et al. 2010:664): (1) establishing the measurement model's acceptable levels of GOF and (2) finding specific evidence of construct validity. Therefore, the study proceeded accordingly and used CFA to assess the hypothesised measurement instrument. To establish GOF, the study reported on the following indices, which should provide adequate model fit evidence (Hair et al. 2010:672; Hoe 2008:77): the chi-square $\left(\chi^{2}\right)$ value, degrees of freedom (df), one absolute index - the root mean square error of approximation (RMSEA), one increment index - comparative fit index (CFI) and the standardised root mean square residual (SRMR).

Given the high sensitivity of $\chi^{2}$ to sample size, especially if the sample size is more than 200, the ratio between $\chi^{2}$ and $\mathrm{df}$ $\left(\chi^{2} / \mathrm{df}\right)$, which in AMOS appears as the Chi-Square minimum discrepancy divided by its degrees of freedom (CMIN/DF), was used to solve this limitation of $\chi^{2}$, and a ratio of 3 or less was considered to be a reasonably good indicator of model fit (Byrne 2010; Hoe 2008). Values for RMSEA range from 0.00 to 1.00 , with values $<0.08$ indicating acceptable model fit, although a more recent publication places a stringent upper limit of 0.07 (Steiger 2007). Values for CFI range from 0.00 to 1.00 , with values $\geq 0.95$ suggesting acceptable model fit, although CFI $\geq 0.90$ may still be meaningful (Bagozzi 2010). SRMR values also range from 0.00 to 1.00 , with values $\leq 0.08$ suggesting acceptable fit while values falling below 0.05 would be indicative of well-fitting models (Byrne 2010; Hooper et al. 2008). The fit indices reveal whether the postulated model fits the data or not. An inadequate fit of the model could further be investigated to detect the source(s) of misfit. The focus of the assessment was placed on parameter estimates (assessing the fit of individual parameters) using the following three criteria (Byrne 2010): these estimates' feasibility, standard errors' appropriateness and these estimates' statistical significance.

On feasibility of parameter estimates, the assessment was carried out through a consideration of viability of estimated values for parameters (i.e. whether estimates indicate correct 
sign and size, and are consistent with theory; Byrne 2010)). According to Byrne (2010:67), parameters demonstrating 'unreasonable estimates are correlations $>1.00$, negative variances, and covariances or correlation matrices that are not positive definite'. In this respect, estimates not meeting the criteria are candidates for deletion as they are considered non-viable. The second step considered the appropriateness of standard errors, which indicate the precision with which a parameter was estimated, with small values suggesting accurate estimation' (Byrne 2010:67). Excessively large or small standard errors are an indication of poor model fit, although currently there are no definitive criteria to determine 'small' and 'large' (Jöreskog \& Sörbom 1989). The third step involved the testing of the statistical significance of parameter estimates. This was performed through the assessment of critical ratio (CR) values of these estimates. Those parameter estimates with $\mathrm{CR}<1.96$ in absolute terms are considered statistically non-significant.

\section{Assessment of multivariate normality and outliers}

Based on the large sample theory, the conduct of CFA or SEM analyses is generally premised on the assumption that the data are multivariate normal (Byrne 2010), an assumption which is specifically required in the use of AMOS (Arbuckle 2007). Of particular concern in the use of CFA or SEM is the situation when the data are multivariate kurtotic; in other words, both the tails and the picks of the multivariate distribution of the observed variables differ from the ones that are characteristic of a multivariate normal distribution (Byrne 2010). Therefore, it is procedurally expected that one inspects the normality of data prior to conducting any analyses. The study estimated multivariate normality of the data and also considered the extent of kurtosis and skewness (Sharma \& Sharma 2013). Outliers, that is, cases whose scores are substantially different from all the others (Byrne 2010) are a likely cause of data skewness (McDonald \& Ho 2002). Serious multivariate outliers make it inappropriate to analyse the data using the maximum likelihood (ML) estimation method and CFA processes. To detect any outliers, Mahalanobis squared distance values $\left(D^{2}\right)$ were computed for each case, after which the resultant $D^{2}$ values were reviewed. The study considered outliers in terms of their inclusion or deletion; these were detected from the univariate distribution of the variables. Factor scores can also be used to detect outliers (Bollen \& Arminger 1991). According to the conventional rule of thumb, 'data may be assumed to be normal if skew and kurtosis is within the range of \pm 1.0 (some say \pm 1.5 or even 2.0$)^{\prime}$ (Schumacker \& Lomax 2010:69). However, some scholars have suggested that the recommended level of skewness be a maximum of 2 and of kurtosis a maximum of 7 for a CFA with ML estimation (Curran, West \& Finch 1996; Sharma \& Sharma 2013; West, Finch \& Curran 1995).

Bayesian estimation of hypothesised measurement model: Because the study used categorical data, the parameter estimates generated by the ML method were compared with those generated using the Bayesian estimation method in order to assess the biasness of the ML-derived estimates (Byrne 2010). If the Bayesian estimates are no different from the ML estimates, then this would speak well for the validity of the hypothesised CFA model (Byrne 2010). The given estimation method was used for the final CFA model of the proposed measurement scale.

\section{Results}

The sample consisted of more men $(66.7 \%)$ than women $(33.3 \%)$, while in terms of the management level of participants, those at senior management level were 19.2\%, at middle management $43.8 \%$ and at junior management $37 \%$. A total of $75.5 \%$ reported managing others. Only $24.5 \%$ of those who were in management reported that they did not manage others (i.e.. these were also managers but were not managing other people because of the nature of their operations). For instance, in some organisations, such managers included Fund Managers, Human Resources Managers, Research and Documentation Managers and Information Technology Managers. In terms of educational levels, the majority of the participants reported that they had additional qualifications after grade 12 (47.5\%), followed by those who reported that they were degree holders $(28.6 \%)$, those with a postgraduate qualification $(16.9 \%)$, a grade 12 qualification (5.7\%) and those who indicated they had attained less than a grade 12 qualification $(1.2 \%)$. In terms of years at the organisation, $46.7 \%$ of the respondents had spent up to 5 years, 26.2\% between 6 and 10 years while $27.1 \%$ had spent 10 years or more.

As regards organisational data, the study involved organisations in eight different economic sectors: banking/ financial $(27.9 \%)$, service $(23.2 \%)$, manufacturing (19.5\%), agriculture/agro industry $(11.8 \%)$, tourism/hospitality $(7.6 \%)$, communication $(5.6 \%)$, mining $(2.3 \%)$ and energy $(2.2 \%)$. The age of organisations ranged from 4 to 150 years (mean age $32.78 ; \mathrm{SD}=23.99$ ). In terms of venture life cycle, the sampled organisations could be categorised as follows: $20.4 \%$ experiencing early growth (4-10 years), $11.9 \%$ in the maturity phase (11 to $>15)$ and $67.6 \%$ in the harvest/stability phase ( 16 to $>20$ years). In relation to data normality, Table 2 shows that skewness ranged from 0.869 to 0.155 while kurtosis ranged from -0.250 to -1.220 . Therefore, the findings clearly suggested that the values were all within the recommended level (skewness maximum 2 and kurtosis maximum 7) for a CFA with ML estimation (Curran et al. 1996; Sharma \& Sharma 2013; West et al. 1995).

However, although the distribution of the observed variables was univariate normal, there was still the possibility that the

TABLE 2: Assessment of normality (Group number 1).

\begin{tabular}{lcccccc}
\hline Variable & Min & Max & Skew & CR & Kurtosis & CR \\
\hline EA1 & 1.000 & 5.000 & 0.869 & 9.013 & -0.327 & -1.698 \\
EA2 & 1.000 & 5.000 & 0.155 & 1.607 & -1.220 & -6.327 \\
EA3 & 1.000 & 5.000 & 0.753 & 7.809 & -0.250 & -1.295 \\
EA4 & 1.000 & 5.000 & 0.800 & 8.306 & -0.412 & -2.135 \\
Multivariate & - & - & - & - & 4.454 & 8.170 \\
\hline
\end{tabular}

Source: Computed AMOS Graphics

$\mathrm{CR}$, critical ratio. 
multivariate distribution could be multivariate normal (West et al. 1995). Therefore, the researchers conducted a further assessment of the index of multivariate kurtosis and its CR, the bottom of the last two columns, respectively, in the AMOS output indicated in Table 2 (Byrne 2010). The CR value represented Mardia's normalised estimate (z-statistic) of multivariate kurtosis, and according to Bentler (2005), values $>5.00$ are indicative of data that are not normally distributed. In this respect, the sample's CR value of 8.170 was suggestive of its multivariate non-normality. To avoid the likelihood of interpretational problems because of the evidence of multivariate kurtosis (Byrne 2010), the estimations were undertaken using the ML method, while the final CFA model for the measurement scale was subjected to bootstrapping to compare it with the ML-derived estimates (Byrne 2010). The results of this approach supported the ML-derived estimates as interpretable. Assessment of outliers using the Mahalanobis squared distance values also showed minimal evidence of serious multivariate outliers; therefore, the data could be analysed using the ML estimation method and CFA processes.

Measurement reliability and validity: The CFA processes were used to determine whether the hypothesised structure provided a good fit to the data, that is, whether a relationship existed between the observed variables and the underlying latent or unobserved construct entrepreneurial actions. As may be observed from Figure 2, the SMCs for the individual

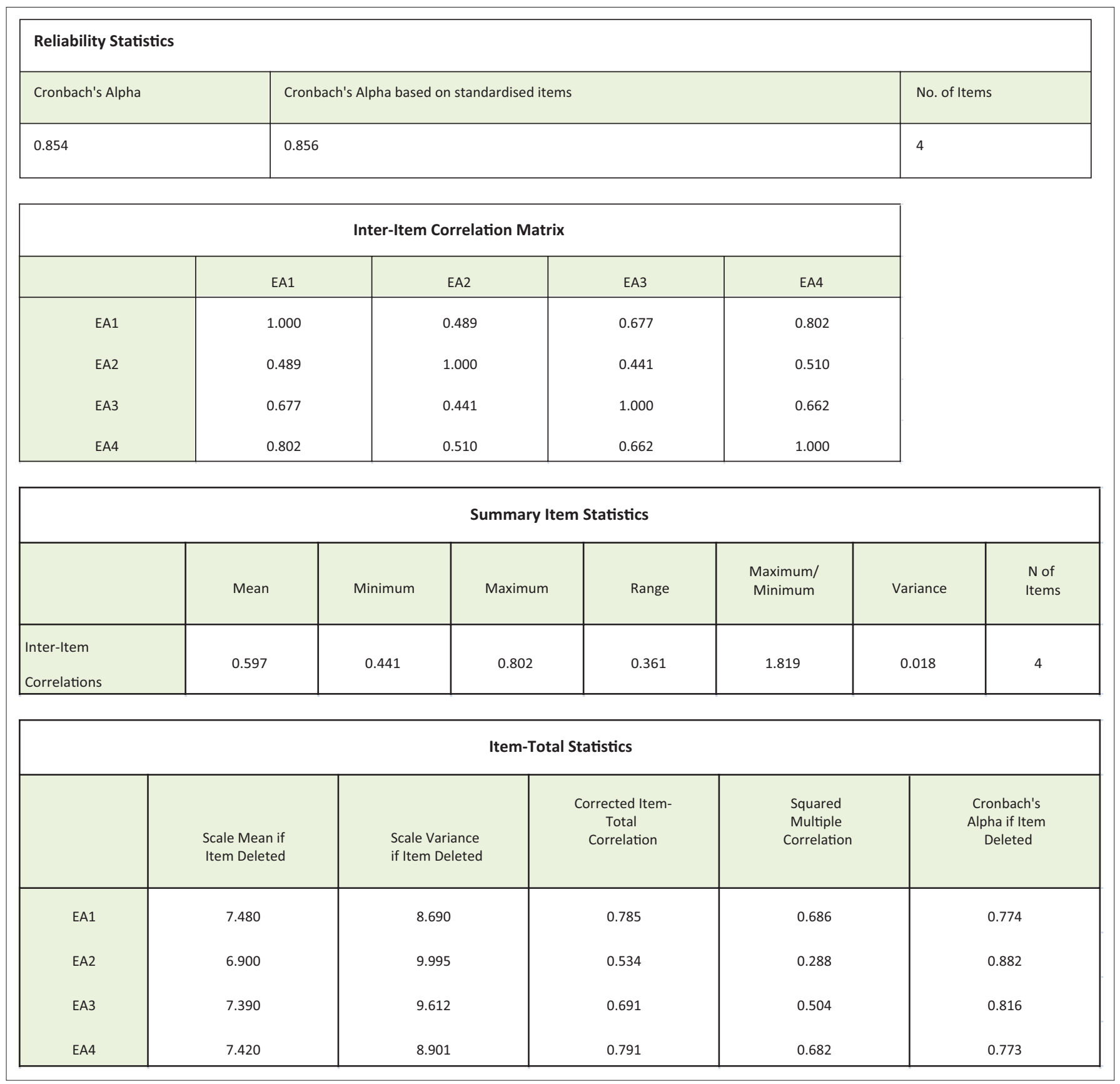

Source: Computed SPSS Descriptive Statistics

FIGURE 2: Measurement reliability statistics. 
items ranged from 0.316 to 0.805 , well above the acceptable result of $\geq 0.20$ for all the four items.

The SMCs for the individual items ranged from 0.316 to 0.805 , well above the acceptable statistic of $\geq 0.20$ for all the four items. The high SMCs for the individual items were suggestive of item reliability (Bagozzi \& Yi 2012). Furthermore, Cronbach's alpha of 0.854 (mean $=9.73 ; \mathrm{SD}=3.97)$ shown in Figure 2 for the four items also confirmed the scale's reliability, which was well above the threshold for assuming item homogeneity.

In evaluating the CFA model, a step-by-step methodology was followed to eventually reach the conclusion that the measuring instrument could be deemed as valid and reliable as will be further discussed in the practical discussion. Figure 3 depicts the CFA results for the measurement model. The estimation process for the model converged and the solution was admissible. There were no post hoc modifications indicated from the analysis because of the excellent fit indices reflected in Table 3; therefore, the model was not re-specified.

The findings demonstrated that the CFA model fitted the data very well as may be observed from the fit indices recorded in Table 3: $X^{2}=2.981$, df $=2$, SRMR $=0.0088$, $\mathrm{CFI}=0.999$ and $\mathrm{RMSEA}=0.028$.
Furthermore, all the parameter estimates were significant and had positive and acceptable values, as presented in Figure 4. As indicated by the critical values, which were greater than 1.96, all the non-standardised parameter estimates (factor loadings) were statistically significant, while all the estimates were positive, as originally hypothesised.

All the factor and error variances were significant. No statistically significant discrepancy was indicated between the hypothesised model and the data because all the standardised residual covariances were below 2.58 and all the residual covariances were relatively small. The ML parameter estimates were also confirmed to be valid through a comparison with those derived using the Bayesian estimation method (results not included). The findings revealed that the Bayesian estimates for the hypothesised CFA model for entrepreneurial actions for sustainable CE were no different from the ML estimates, which speaks well for the validity of the model (Byrne 2010).

\section{Discussion}

The sample comprised managers from several organisations within eight different economic sectors, while the organisations represented by these participants had been in existence for at least 4 years. As regards biographical

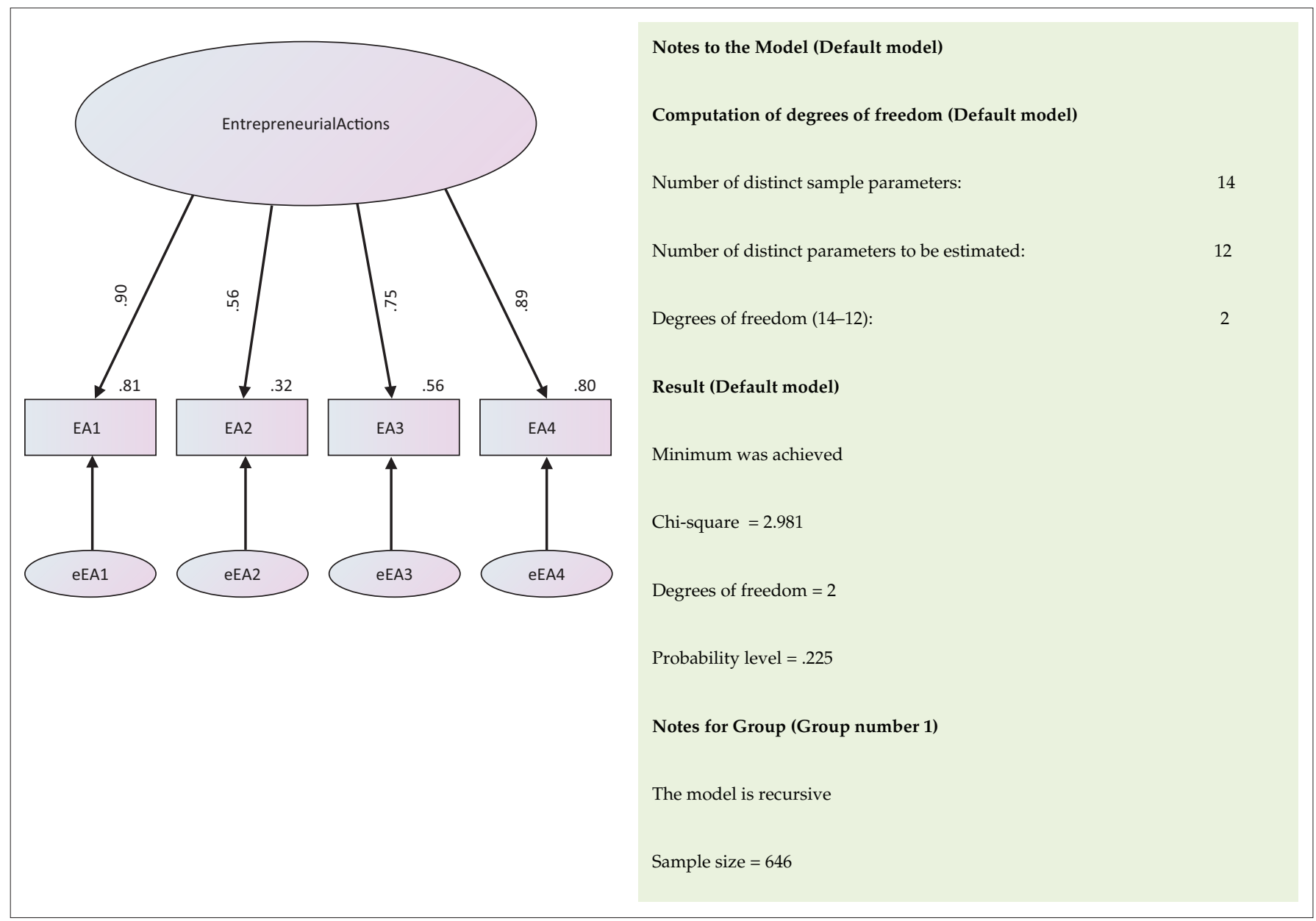

Source: AMOS Graphics

FIGURE 3: Confirmatory Factor Analysis model for entrepreneurial actions. 
TABLE 3: Fit indices of Confirmatory Factor Analysis model for entrepreneurial actions.

\begin{tabular}{lcccccc}
\hline Model & $\boldsymbol{x}^{2}$ & d.f & $\boldsymbol{P}$ & CMIN/DF & SRMR & CFI \\
\hline Hypothesised Model & 2.981 & 2 & 0.225 & 1.491 & 0.0088 & 0.999 \\
& & & & 0.028 & PCLOSE (0.645) \\
\hline
\end{tabular}

Source: Computed AMOS Graphics

$x^{2}$, chi-square; d.f, degrees of freedom; P, $p$-value; CMIN/DF, Chi-Square minimum discrepancy divided by its degrees of freedom; SRMR, standardised root mean square residual; CFI, comparative fit index; RMSEA, root mean square error of approximation.

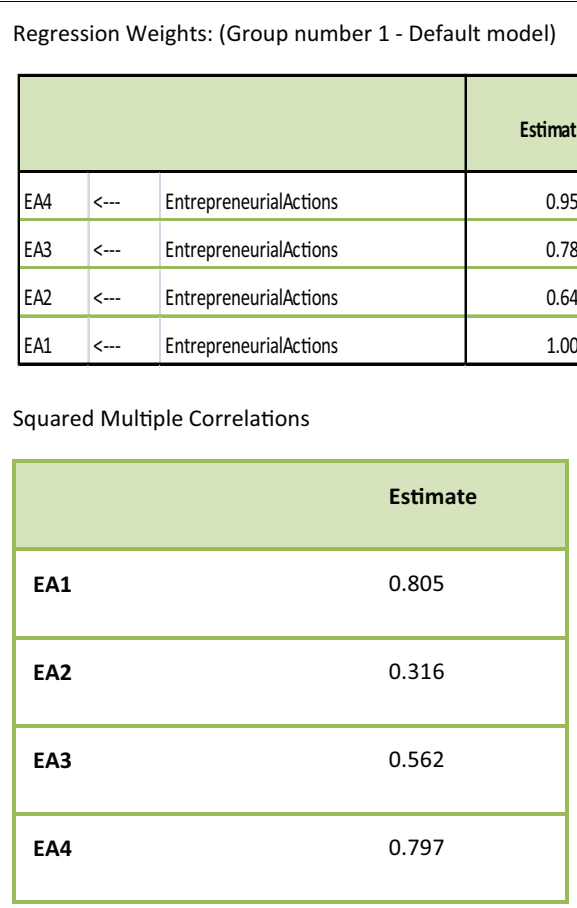

Residual Covariances

\begin{tabular}{|lllll|}
\hline & EA4 & EA1 & EA2 & EA3 \\
\hline EA4 & 0.000 & & \\
\hline EA1 & 0.002 & 0.000 & & \\
\hline EA2 & 0.012 & -0.023 & 0.000 & \\
\hline EA3 & -0.010 & 0.005 & 0.028 & 0.000 \\
\hline
\end{tabular}

Variances
\begin{tabular}{|l|r|r|r|l|l|}
\hline & Estimate & S.E. & C.R. & P & Label \\
\hline EntrepreneurialActions & 1.18 & 0.084 & 13.976 & $* * *$ & par_8 \\
\hline eEA4 & 0.276 & 0.029 & 9.468 & $* * *$ & par_9 \\
\hline eEA2 & 1.063 & 0.062 & 17.081 & $* * *$ & par_10 \\
\hline eEA1 & 0.285 & 0.031 & 9.148 & $* * *$ & par_11 \\
\hline eEA3 & 0.563 & 0.036 & 15.467 & $* * *$ & par_12 \\
\hline
\end{tabular}

Standardised Residual Covariances

\begin{tabular}{|lllll|}
\hline & EA1 & EA2 & EA3 & EA4 \\
\hline EA1 & 0.000 & & \\
\hline EA2 & -0.350 & 0.000 & & \\
\hline EA3 & 0.082 & 0.461 & 0.000 & \\
\hline EA4 & 0.027 & & & \\
\hline
\end{tabular}

Source: Computed AMOS Graphics

FIGURE 4: Parameter estimates for Confirmatory Factor Analysis model for entrepreneurial actions.

characteristics of the sample, the majority of the participants were middle managers followed by junior and senior managers, most of whom managed others. The fact that the majority were middle managers added value to the research as these managers play an important and strategic role in instigating entrepreneurial actions within an organisation (Kuratko et al. 2005a; Ren \& Guo 2011).

In addition, most of the management participants had attained non-degree qualifications beyond grade 12 $(47.5 \%)$, while a good number of them had obtained university degrees and postgraduate qualifications (45.5\%), whereas a few of them (6.9\%) had qualifications just up
Standardised Regression Weights

\begin{tabular}{|l|l|l|r|}
\hline & & & Estimate \\
\hline EA4 & $<--$ & EntrepreneurialActions & 0.893 \\
\hline EA3 & $<--$ & EntrepreneurialActions & 0.750 \\
\hline EA2 & $<--$ & EntrepreneurialActions & 0.562 \\
\hline EA1 & $<--$ & EntrepreneurialActions & 0.897 \\
\hline
\end{tabular}
0.897 
It will be recalled that the overall objective of the study was to assess the psychometric attributes of the hypothesised measurement model using CFA procedures. Specifically, the study aimed at determining the model's reliability and validity, as well as its intercultural psychometric portability. The findings suggested that the measurement model for entrepreneurial actions for sustainable CE possessed acceptable construct validity and reliability. Furthermore, the measurement scale provided evidence of convergent validity in that each item had significant loading on its specified factor (Van Dyne \& LePine 1998). A summary of the tested hypotheses regarding their rejection or acceptance is provided in Table 4, which shows that all the four hypotheses were accepted.

Measurement reliability testing: The hypothesised CFA model displayed high reliability looking at the model's SMCs: EA1 (0.805), EA2 (0.316), EA3 (0.562) and EA4 (0.797). Clearly, the SMCs for all four items were well above the acceptable threshold of $\geq 0.20$, suggesting that the scale possessed high reliability. Furthermore, the Inter-Item Correlation matrix indicated that all four items had positive values, suggesting that they were measuring the same underlying characteristics, while the corrected item-total correlation values presented in Figure 2 for item-total statistics indicated that each item had a high correlation with the total score of the scale, ranging from 0.534 to 0.791 , which values were well above the cut-off of 0.3 (Pallant 2010:100). Furthermore, the measurement scale's mean inter-item correlation value of 0.597 , with minimum and maximum values being 0.441 and 0.802 , respectively, is suggestive of a strong relationship among the items (Pallant (2010:100).

A closer look at the column headed Alpha If Item Deleted, which indicates the impact of removing each item from the scale, clearly showed that deleting the newly added item EA4 ('I am satisfied with the outcomes of my organisation's entrepreneurial activities as they meet expectation') would reduce the scale's overall reliability from $\alpha=0.85$ to $\alpha=0.77$, hence revealing the importance of this added item. The study's first hypothesis, stating that the proposed measurement instrument has acceptable internal consistency, was therefore accepted.

Construct validity testing: The findings indicated that the hypothesised measurement model possessed high convergent validity in that the non-standardised factor loading estimates of the model were all statistically significant, as indicated by the critical values which were greater than 1.96 , while the standardised factor loadings for all the four items were $\geq 0.5$ : EA1 (0.897), EA2 (0.562), EA3 (0.750) and EA4 (0.893). Furthermore, the model's AVE of 0.62 (62.01\%) again suggested adequate convergence for the hypothesised measurement model. The model's discriminant validity was also established because the model was found acceptable, with excellent fit indices, while its parameter estimates were all significant and acceptable. The values for the residual covariances were all less than 0.10 (Figure 4), suggesting that the model was correct (Kline 2011). Therefore, the model actually presented its own evidence of convergent and discriminant validity as it had excellent fit (Anderson \& Gerbing 1988; Shook et al. 2004). Therefore, the second hypothesis, stating that the proposed measurement instrument has acceptable construct validity, was accepted.

Unidimensionality of the measurement model: The findings demonstrated that there were no redundant items as the standardised factor loadings for all the items were statistically significant and $\geq 0.50$, suggesting measurement unidimensionality (Nazim \& Ahmad 2013:4), hence affirming the study's third hypothesis that the proposed measurement instrument is a unidimensional scale.

Psychometric attributes of the measurement instrument: The findings validated the measurement instrument as maintaining its psychometric attributes across cultures and countries, consequently supporting the study's fourth hypothesis that the proposed measurement instrument has acceptable intercultural psychometric portability.

Potentially, the validated measurement instrument will benefit researchers and academicians in the domain of sustainable CE as it could be used to assess an organisation's entrepreneurial actions. Managers might also use the measured indices to ensure appropriate planning and execution of their $\mathrm{CE}$ strategies. However, in order for members of top management to instigate entrepreneurial actions that lead to enhanced organisational competitiveness, they must first and foremost embrace sustainable CE and provide a strong support structure as well as appropriate resources (Ireland, Covin \& Kuratko 2009) and must themselves have a thorough understanding of both the internal and external environments (Hornsby, Kuratko \& Zahra 2002). Furthermore, it is important that all levels of management are involved (Holt, Rutherford \& Clohessy 2007) while the entire organisation must be readied for the $\mathrm{CE}$ experience in terms of its culture and values as well as reward and motivation schemes (Thornberry 2001). However, as Kelly (2011:73) contends, 'the majority of firms

TABLE 4: Summary of results relating to tested hypotheses.

\begin{tabular}{ll}
\hline Hypothesis Tested & \multicolumn{1}{c}{ Accepted/Rejected } \\
\hline $\mathrm{H}_{1}$ & $\begin{array}{l}\text { The proposed measurement instrument for entrepreneurial actions for sustainable corporate entrepreneurship has acceptable } \\
\text { internal consistency. }\end{array}$ \\
$\mathrm{H}_{2}$ & $\begin{array}{l}\text { The proposed measurement instrument for entrepreneurial actions for sustainable corporate entrepreneurship has acceptable } \\
\text { construct validity. }\end{array}$ \\
$\mathrm{H}_{3}$ & $\begin{array}{l}\text { The proposed measurement instrument for entrepreneurial actions for sustainable corporate entrepreneurship is a unidimensional } \\
\text { scale. }\end{array}$ \\
$\mathrm{H}_{4}$ & $\begin{array}{l}\text { The proposed measurement instrument for entrepreneurial actions for sustainable corporate entrepreneurship has acceptable } \\
\text { intercultural psychometric portability. }\end{array}$ \\
\hline
\end{tabular}

Source: Part of Study Findings 
possess a general resistance to these initiatives'. Therefore, organisations that do not exhibit entrepreneurial actions for sustainable CE will undoubtedly not reap the benefits of having an entrepreneurial environment that brings about enhanced organisational performance and will instead blame the entrepreneurship phenomenon, mistakenly concluding that it does not succeed.

\section{Study limitations}

Undoubtedly, there are a number of limitations to this study. However, these could offer opportunities for new research directions.

One of the limitations was that once the industry strata had been identified, selection of participating individuals was carried out using a non-probability sampling method in order to satisfactorily meet sampling objectives (Cooper \& Schindler 2008:396). However, the use of a non-probability sampling procedure does not reflect a true cross-section of the population and is acknowledged as a limitation of this study.

Secondly, the piloting of the measurement instrument should have been much more comprehensive, using a relatively large sample size, say of at least 30 participants (Schriesheim et al. 1993). However, this was not done because of the cost implications; it is consequently acknowledged as another important limitation of the study. In addition, it is very likely that the contextual meaning of the items for the hypothesised measurement instrument may have been interpreted differently by some respondents, thereby detracting from the intended outcome in terms of responses. The piloting phase could have dealt with this aspect as well.

Thirdly, the study's objective was to assess reliability and validity of the hypothesised measurement of entrepreneurial actions for sustainable $\mathrm{CE}$, which incorporates the threeitem scale developed by Kuratko et al. (2005a) to measure managers' entrepreneurial actions as well as the added fourth item developed by the researchers. The measures of entrepreneurial actions in the original scale developed by Kuratko et al. (2005a) tend to be simplistic. For instance, one can argue that merely suggesting new ideas does not necessarily make such ideas into actions and it may not really matter whether such ideas are approved or not. Similarly, the item ('I am satisfied with the outcomes of my organisation's entrepreneurial activities as they meet expectation') developed by the researchers may benefit from further research. In this respect, although the measurement instrument showed excellent reliability and construct validity, more research still needs to be undertaken in order to refine the instrument theoretically and empirically, based on the premise mentioned earlier that entrepreneurial actions are the conduit through which CE is practiced in existing organisations (Hitt et al. 2001). Moreover, satisfaction with organisational outcomes in relation to the implemented entrepreneurial activities is a critical aspect of these entrepreneurial actions for sustainable CE (Simon \& Shrader 2012:291).

\section{Conclusion and recommendations}

The focus of this research has fallen on validating the hypothesised measurement instrument for managers' entrepreneurial actions for sustainable CE. The study findings showed that the hypothesised single-factor measurement instrument with four indicator variables for entrepreneurial actions had acceptable construct validity and reliability, as evidenced by the excellent fit and statistically significant loading for each item on the factor (Van Dyne \& LePine 1998), as well as acceptable SMCs. All the parameter estimates were statistically significant and acceptable, while a Cronbach's alpha coefficient of 0.85 suggested high internal consistency reliability. Therefore, these findings suggest that the proposed measurement scale adequately represented the construct. The CFA processes performed demonstrated that the hypothesised measurement model was acceptable as it achieved the required unidimensionality, reliability, validity and fit indices. Furthermore, the study's findings have also validated the measurement instrument in terms of maintaining its psychometric attributes across cultures and countries.

To our knowledge, the hypothesised measurement scale has never been subjected to a vigorous assessment previously, regarding its reliability and validity. Therefore, this study's findings are valuably instructive. Our study may lead to improved understanding and measurement of CE strategy as the findings provide an index that may be useful in diagnosing entrepreneurial actions that could lead to sustainable CE. However, notwithstanding these useful findings, the researchers are of the view that more research should be undertaken for further measurement refinement using data from diverse samples.

Additional study could also lead to the development of a more generalisable scale with sound psychometric attributes and unlimited in scope across cultures and countries. Future studies could also focus on assessing the extent to which managers' entrepreneurial actions influence sustainable CE and sustained organisational performance.

\section{Acknowledgements Competing interests}

The authors declare that they have no financial or personal relationships which may have inappropriately influenced them in writing this article.

\section{Authors' contributions}

C.M.M. was led in the conceptualisation and design of the study, conducted data collection and analysis, and reporting. J.J.v.V. supervised the study, made conceptual contributions and participated in refining the study structure.

\section{References}

Anderson, J.C. \& Gerbing, D.W., 1988, 'Structural equation modelling in practice: A review and recommended two-step approach', Psychological Bulletin 103(3), 411-423. http://dx.doi.org/10.1037/0033-2909.103.3.411

Arbuckle, J., 2007, Amos 16.0 user's guide, SPSS, Chicago, IL. 
Bagozzi, R.P., 2010, 'Structural equation models are modelling tools with many ambiguities: Comments acknowledging the need for caution and humility in their use', Journal of Consumer Psychology 20(2), 208-214. http://dx.doi.org/10.1016/ j.jcps.2010.03.001

Bagozzi, R.P. \& Yi, Y., 2012, 'Specification, evaluation, and interpretation of structural equation models', Journal of the Academy of Marketing Science 40(1), 8-34. $\mathrm{http} / / / \mathrm{dx}$.doi.org/10.1007/s11747-011-0278-x

Bagozzi, R.P., Yi, Y. \& Phillips, L.W. 1991. 'Assessing construct validity in organisational research', Administrative Science Quarterly, 36(3), 421-458.

Bentler, P.M., 2005, EQS 6.1, Multivariate Software, Encino, CA.

Bollen, K.A. \& Arminger, G., 1991, 'Observational residuals in factor analysis and structural equation models', in P.V. Marsden (ed.), Sociological methodology, pp. 235-262, Blackwell, Cambridge, MA.

Brown, T.A., 2006, CFA for applied research, Guilford Press, New York.

Burns, R.B. \& Burns, R.A., 2011, Business research methods and statistics using SPSS, SAGE Publications, London.

Byrne, B.M., 2004, 'Testing for multigroup invariance using AMOS graphics: A road less travelled', Structural Equation Modeling: A Multidisciplinary Journal 11(2), 272-300. http://dx.doi.org/10.1207/s15328007sem1102_8

Byrne, B.M., 2010, Structural equation modeling with AMOS: Basic concepts, applications, and programming, 2nd edn., Routledge, New York.

Central Statistics Office of Zambia, 2009, Employment and earnings inquiry report Labour Statistics Branch, Central Statistics Office: Lusaka.

Chen, C.C., Greene, P. \& Crick, A., 1998, 'Does entrepreneurial self-efficacy distinguish entrepreneurs from managers?', Journal of Business Venturing 13, 295-316. http://dx.doi.org/10.1016/S0883-9026(97)00029-3

Cooper, D.R. \& Schindler, P., 2008, Business research methods, 10th edn., McGrawHill, New York.

Corbett, A., Covin, J.G., O'Connor, G.C. \& Tucci, C.L., 2013, 'Corporate entrepreneurship: State-of-the-art research and a future agenda', Journal of Product Innovation and Management 30(5), 812-820. http://dx.doi.org/10.1111/jpim.12031

Covin, J.G. \& Lumpkin, G.T., 2011, 'Entrepreneurial orientation theory and research: Reflections on a needed construct', Entrepreneurship Theory and Practice 35(5), 855-872. http://dx.doi.org/10.1111/j.1540-6520.2011.00482.x

Covin, J.G. \& Miles, M.P., 1999, 'Corporate entrepreneurship and the pursuit of competitive advantage', Entrepreneurship Theory and Practice 23(3), 47-63.

Covin, J.G. \& Slevin, D.P., 1991, 'A conceptual model of entrepreneurship as firm behaviour', Entrepreneurship: Theory and Practice 16, 7-24.

Curran, P.J., West, S.G. \& Finch, J.F., 1996, 'The robustness of test statistics to nonnormality and specification error in confirmatory factor analysis', Psychological Methods 1(1), 16-29. http://dx.doi.org/10.1037/1082-989X.1.1.16

Davidsson, P., 1991, 'Continued entrepreneurship: Ability, need and opportunity as determinants of small firm growth', Journal of Business Venturing 6(6), 405-429. http://dx.doi.org/10.1016/0883-9026(91)90028-C

De Jong, J.P.J., Parker, S.K., Wennekers, S. \& Wu, C., 2011, Corporate entrepreneurship at the individual level: Measurement and determinants, EIM Research Reports, EIM, Zoetermeer

Dess, G.G., Lumpkin, G.T. \& Covin, J.G., 1997, 'Entrepreneurial strategy making and firm performance: Tests of contingency and configurational models', Strategic Management Journal 18(9), 677-695. http://dx.doi.org/10.1002/(SICI)10970266(199710)18:9<677::AID-SMJ905>3.0.CO;2-Q

Dolnicar, S. \& Grün, B., 2007, 'Cross-cultural differences in survey response patterns', International Marketing Review 24(2), 127-143. http://dx.doi.org/10.1108/ 02651330710741785

Garson, G.D., 2012, Structural equation modeling, Blue Book Series, Statistical Associates Publishing, Asheboro, NC.

Hagell, P., 2014, 'Testing rating scale unidimensionality using the principal component analysis (PCA)/t-test protocol with the Rasch model: The primary of theory ove statistics', Open Journal of Statistics 4(6), 456-465. http://dx.doi.org/10.4236/ ojs.2014.46044

Hair, J.F., Black, W.C., Babin, B.J. \& Anderson, R.E., 2010, MDA: A global perspective, 7th edn., Prentice Hall, Upper Saddle River, NJ.

Hitt, M.A., Ireland, R.D., Camp, S.M. \& Sexton, D.L., 2001, 'Strategic entrepreneurship: Entrepreneurial strategies for wealth creation', Strategic Management Journal 22(6-7), 479-491. http://dx.doi.org/10.1002/smj.196

Hitt, M.A., Ireland, R.D., Sirmon, D.G. \& Trahms, C.A., 2011, 'Strategic entrepreneurship: Creating value for individuals, organisations and society', Academy of Managemen Perspective 25(2), 57-75. http://dx.doi.org/10.5465/AMP.2011.61020802

Hoe, S.L., 2008, 'Issues and procedures in adopting structural equation modeling technique', Journal of Applied Quantitative Methods 3(1), 76-83.

Holt, D.T., Rutherford, M.W. \& Clohessy, G.R., 2007, 'Corporate entrepreneurship: An empirical look at individual characteristics, context, and process', Journal of Leadership and Organizational Studies 13(4), 40-54. http://dx.doi.org/10.1177/ 10717919070130040701

Hooper, D., Coughlan, J. \& Mullen, M.R., 2008 'Structural equation modelling: Guidelines for determining model fit', The Electronic Journal of Business Research Methods 6(1), 53-60.

Hornsby, J.S., Kuratko, D.F., Holt, D.T. \& Wales, W.J., 2013, 'Assessing a measurement of organisational preparedness for corporate entrepreneurship', Journal of Product Innovation Management 30(5), 937-955. http://dx.doi.org/10.1111/ jpim.12038
Hornsby, J.S., Kuratko, D.F., Shepherd, D.A. \& Bott, J.P., 2009, 'Managers' corporate entrepreneurial actions: Examining perception and position', Journal of Business Venturing 24, 236-247. http://dx.doi.org/10.1016/j.jbusvent.2008.03.002

Hornsby, J.S., Kuratko, D.F. \& Zahra, S.A., 2002, 'Middle managers' perception of the internal environment for corporate entrepreneurship: Assessing a measurement scale', Journal of Business Venturing 17, 253-273. http://dx.doi.org/10.1016/ S0883-9026(00)00059-8

Ireland, R.D., Covin J.G. \& Kuratko, D.F., 2009, 'Conceptualising corporate entrepreneurship strategy', Entrepreneurship Theory and Practice 33(1), 19-46. $\mathrm{http}: / /$ dx.doi.org/10.1111/j.1540-6520.2008.00279.x

Ireland, R.D., Hitt, M.A., Camp, S.M. \& Sexton, D.L., 2001, 'Integrating entrepreneurship and strategic management actions to create firm wealth', The Academy of Management Executive 15(1), 49-63. http://dx.doi.org/10.5465/AME.2001. 4251393

Jöreskog, K.G. \& Sörbom, D., 1989, LISREL 7: User's reference guide, Scientific Software Inc., Chicago, IL.

Kelly, D., 2011, 'Sustainable corporate entrepreneurship: Evolving and connecting with the organisation', Business Horizons 54(1), 73-83. http://dx.doi.org/10.1016/ j.bushor.2010.09.003

Kline, R.B., 2011, Principles and practice of structural equation modeling, 3rd edn., Guilford Press, New York.

Kuratko, D.F., 2013, Entrepreneurship: Theory, process, and practice, 9th edn., Cengage Learning, South-Westen Mason, $\mathrm{OH}$.

Kuratko, D.F., Hornsby, J.S. \& Goldsby, M.G., 2004, 'Sustaining corporate entrepreneurship: Modelling perceived implementation and outcome comparisons at organisational and individual levels', The International Journal of Entrepreneurship and Innovation 5(2), 77-89. http://dx.doi.org/10.5367/ 000000004773863237

Kuratko, D.F., Ireland, R.D. \& Hornsby, J.S., 2001, 'Improving firm performance through entrepreneurial actions: Acordia's corporate entrepreneurship strategy', The Academy of Management Executive 15(4), 60-71. http://dx.doi.org/10.5465/ AME.2001.5897658

Kuratko, D.F., Hornsby, J.S. \& Bishop, J.W., 2005a, 'Managers' corporate entrepreneurial actions and job satisfaction', International Entrepreneurship and Management Journal 1, 275-291. http://dx.doi.org/10.1007/s11365-005-2589-1

Kuratko, D.F., Ireland, R.D., Covin, J.G. \& Hornsby J.S., 2005b, 'A model of middle-leve managers' entrepreneurial behaviour', Entrepreneurship Theory and Practice 29(6), 699-716. http://dx.doi.org/10.1111/j.1540-6520.2005.00104.x

Kusumsiri, S.N. \& Jayawardane, A.K.W., 2013, 'Defining entrepreneurship: Operational considerations', Proceedings of the National Conference on Technology and Management 2, 26-31.

McDonald, R.P. \& Ho, M.H.R., 2002, 'Principles and practice in reporting structural equations analyses', Psychological Methods 7(1), 64-82. http://dx.doi.org/ 10.1037/1082-989X.7.1.64

Menzel, H.C., Aaltio, I. \& Ulijn, J.M., 2007, 'On the way to creativity: Engineers as intrapreneurs in organizations', Technovation 27(12), 732-743. http://dx.doi.org/ 10.1016/j.technovation.2007.05.004

Miles, M.P., Munilla, L.S. \& Darroch, J., 2009, 'Sustainable corporate entrepreneurship', International Entrepreneurship Management Journal 5(1), 65-76. http://dx.doi. International Entrepreneurship Nan
org/10.1007/s11365-008-0074-3

Morris, M.H., Kuratko, D.F. \& Covin, J., 2011, Corporate entrepreneurship and innovation, 3rd edn., South-Western Cengage, Mason, $\mathrm{OH}$.

Nazim, A. \& Ahmad, S., 2013, 'Assessing the unidimensionality, reliability, validity and fitness of influential factors of 8th grade student's mathematics achievement in Malaysia', International Journal of Advance Research 1(2), 1-7.

Nunnally, J.C. \& Bernstein, I.H., 1994, Psychometric theory, McGraw-Hill, New York.

Pallant, J., 2010, SPSS survival manual, 4th edn., Open University Press, England.

Ren, C.R. \& Guo, C., 2011, 'Middle managers' strategic role in the corporate entrepreneurial process: Attention-based effects', Journal of Management 37(6), 1586-1610. http://dx.doi.org/10.1177/0149206310397769

Said, H., Badru, B.B. \& Shahid, M., 2011, 'Confirmatory factor analysis (CFA) for testing validity and reliability instrument in the study of education', Australian Journal of Basic and Applied Sciences 5(12), 1098-1103

Schaltegger, S. \& Wagner, M., 2011, 'Sustainable entrepreneurship and sustainability innovation: Categories and interactions', Business Strategy and the Environment 20(4), 222-237. http://dx.doi.org/10.1002/bse.682

Schriesheim, C.A., Powers, K.J., Scandura, T.A., Gardiner, C.C. \& Lankau, M.J., 1993 Improving construct measurement in management research: Comments and quantitative approach for assessing the theoretical content adequacy of penciland-paper survey-type instruments', Journal of Management 19(2), 385-417. http://dx.doi.org/10.1177/014920639301900208

Schumacker, R.E. \& Lomax, R.G., 2010, A beginner's guide to structural equation modeling, 3rd edn., Routledge, New York.

Sharma, P. \& Chrisman, J.J., 1999, 'Towards a reconciliation of definitional issues in the field of corporate entrepreneurship', Entrepreneurship Theory and Practise 23(3), 11-27.

Sharma, P. \& Sharma, J., 2013, 'Confirmatory factor analysis of Dutch work addiction scale (DUWAS)', Global Business Review 14(2), 211-223. http://dx.doi.org/ 10.1177/0972150913477449

Shepherd, D.A. \& Patzelt, H., 2011, 'The new field of sustainable entrepreneurship: Studying entrepreneurial action linking "what is to be sustained" with "what is to
be developed", Entrepreneurship Theory and Practice 35(1), 137-163. http:// dx.doi.org/10.1111/j.1540-6520.2010.00426.x 
Shook, C.L., Ketchen, D.J., Hult, G.T.M. \& Kacmar, K.M., 2004, 'An assessment of the use of structural equation modeling in strategic management research', Strategic Management Journal 25(4), 397-404. http://dx.doi.org/10.1002/smj.385

Simon, M. \& Shrader, R.C., 2012, 'Entrepreneurial actions and optimistic overconfidence: The role of motivated reasoning in new product introductions', Journal of Business Venturing 27(3), 291-309. http://dx.doi.org/10.1016/ j.jbusvent.2011.04.003

Smith, K.G. \& Di Gregorio, D., 2002, 'Bisociation, discovery and the role of entrepreneurial actions', in M.A. Hitt, R.D. Ireland, S.M. Camp \& D.L. Sexton (eds.) Strategic entrepreneurship: Creating a new mindset, pp. 130-150, Blackwell Publishers, Oxford, UK.

Steiger, J.H., 2007, 'Understanding the limitations of global fit assessment in structura equation modeling', Personality and Individual Differences 42(5), 893-898. http:// dx.doi.org/10.1016/j.paid.2006.09.017

Streiner, D.L., 2003, 'Starting at the beginning: An introduction to coefficient alpha and internal consistency', Journal of Personality Assessment 80(1), 99-103. http:// dx.doi.org/10.1207/S15327752JPA8001_18

Thornberry, N., 2001, 'Corporate entrepreneurship: Antidote or oxymoron?', European Management Journal 19(5), 526-533. http://dx.doi.org/10.1016/S0263-2373(01) 00066-4

Urban, B. \& Nikolov, K., 2013, 'Sustainable corporate entrepreneurship initiatives: A risk and reward analysis', Technological and Economic Development of Economy 19(suppl. 1), S383-\$408.
Urbano, D. \& Turró, A., 2013, 'Conditioning factors for corporate entrepreneurship: An in (ex) ternal approach', International Entrepreneurship and Management 9(3), 379-396. http://dx.doi.org/10.1007/s11365-013-0261-8

Van Dyne, L. \& LePine, J.A., 1998, 'Helping and voice extra-role behaviors: Evidence of construct and predictive validity", Academy of Management Journal 41(1), 108-119. http://dx.doi.org/10.2307/256902

Van Vuuren, J., 2009, The entrepreneurial process, Lecture to ENP821 class on 2009-02-05, Department of Business Management, University of Pretoria, Pretoria.

Van Wyk, R. \& Adonisi, M., 2011, 'An eight-factor solution of the corporate entrepreneurship assessment instrument', African Journal of Business Management 5(8), 3047-3055.

Wensley, A.K.P., Cegarra-Navarro, J.G., Cepeda-Carrion, G. \& Millan, A.G.L., 2011 'How entrepreneurial actions transform customer capital through time: Exploring and exploiting knowledge in an open-mindedness context', International Journal (150. http://dx.doi.org/10.1108/01437721111121279

West, S.G., Finch, J.F. \& Curran, P.J., 1995, 'Structural equation models with non-normal variables: Problems and remedies', in R.H. Hoyle (ed.), Structural equation modelling: Issues and applications, pp. 56-75, SAGE Publications, Newbury Park, CA

Westen, D. \& Rosenthal, R., 2003, 'Qualifying construct validity: Two simple measures', Journal of Personality and Psychology 24(3), 608-618. http://dx.doi.org/10.1037/ 0022-3514.84.3.608

Yoo, B. \& Donthu, N., 2001, 'Developing a scale to measure the perceived quality of an internet shopping site (SITEQUAL)', Quarterly Journal of Electronic Commerce 2(1), 31-47. 